\title{
EDUCAÇÃO EM TEMPO INTEGRAL: UM BREVE PANORAMA
}

\section{ARTIGO DE REVISÃO}

DIAS, Kátia Gonçalves ${ }^{1}$

DIAS, Kátia Gonçalves. Educação em tempo integral: Um breve panorama. Revista Científica Multidisciplinar Núcleo do Conhecimento. Ano 05, Ed. 06, Vol. 02, pp. 3351. Junho de 2020. ISSN: 2448-0959, Link de acesso: https://www.nucleodoconhecimento.com.br/educacao/educacao-em-tempo

\section{RESUMO}

A educação integral é uma importante peça da história da cidadania, logo, do homem, e, dessa forma, é uma temática que tem sido profundamente discutida e os seus conceitos reelaborados ao longo dos anos. Essa proposta tem como objetivo discutir e refletir, a partir de uma revisão da literatura, sobre o Programa Educação em Tempo Integral. Trata-se de um estudo bibliográfico e descritivo. Parte-se da hipótese de que para que a educação seja, de fato integral, apenas aumentar o tempo de permanência na escola não acarreta a formação integral. Considerando esse contexto, o artigo versará sobre os caminhos percorridos pela educação integral, tendo como enfoque o referido programa. Tem se como problema de pesquisa o fato de que a educação integral, ainda hoje, mesmo que tenha se popularizado, é um desafio para o país, devido à falta de recursos e de capacitação dos professores na maioria das escolas, o que justifica a relevância do estudo. Serão apresentadas as políticas públicas sobre a temática e como essa proposta tem se consolidado no Brasil.

Palavras-chave: Escola Integral, estudantes, Políticas Públicas, cidadania.

\footnotetext{
${ }^{1}$ Especialista em O Ensino de Educação Física, pós graduada em Educação Física com ênfase em treinamento desportivo, pós graduada em Nutrição com ênfase em Obesidade e Emagrecimento, Licenciatura plena em Educação Física, Acadêmica de Nutrição.
} 


\section{INTRODUÇÃO}

Um dos pilares da nova metodologia frente às escolas públicas brasileiras é a democracia escolar e um novo caminho se instala na descentralização e a autonomia, atribuindo, às escolas, a responsabilidade de possibilitar a particularidade da administração e organização do acesso à aplicabilidade e controle social (PARO, 2007; LIMA, 2002; SOUZA, 2009). Cabe à comunidade escolar reconhecer e compreender onde focar dentro da escola. A pesquisa irá discutir sobre a educação integral a partir de uma ótica histórica, visando verificar os impactos advindos dessa temática nas unidades escolares, que, em sua maioria, atingem aspectos de responsabilidade e autonomia administrativa, coletividade e engloba decisões. $O$ Brasil é um país cuja miscigenação, a desigualdade, problemas sócio-econômicoculturais interferem nos mais diversos setores, especialmente no setor da educação, que, historicamente, era privilégio daqueles que possuíam capital.

O país obteve ganhos históricos com a criação do Ministério da Educação, órgão do governo federal do país, criado no mandato do presidente Getúlio Vargas, em 1930. Pretendia-se ampliar a educação escolar e tornar o acesso à ela mais viável, sobretudo para as populações mais restritas, atendendo a todos que dela precisavam. Questões sobre a educação extraescolar, saúde pública e apoio médico-social passaram a ser pautas do governo. O MEC passou a lidar apenas com a política nacional da educação, e, com um olhar direcionado, preocupa-se com a preparação para o exercício da cidadania e com as grandes massas da população, ofertando serviços demandados pela sociedade. O MEC impôs muitos programas com o intuito de sanar algumas necessidades imediatas necessárias àquele quadro político-social da época, e, assim, planejou políticas direcionadas à igualdade de oportunidades e à inclusão social (GHANEM, 2004; ARELARO; JACOMINI; CARNEIRO, 2016; PEREIRA; BATISTA, 2016).

A educação integral escolar no país é uma demanda da educação básica e deve ser pública, considerando aspectos de cunho social, cultural e histórico. Visando as transfigurações da sociedade e se firmar em práticas e meditações que tange os métodos que constituem em ajudar na socialização e na cidadania da educação 
brasileira (SANTOS; PEREIRA; MELLO, 2019; MENEZES, 2012; RIBETTO; MAURíCIO, 2009). A relevância do tema se dá em razão do fato que a educação integral e as políticas públicas sustentam o sucesso da mesma e se a proposta de ensino seja viável nas escolas, é possível alcançar as metas objetivadas pelo programa do governo, e, assim, haverá a aprendizagem significativa com seus aprendizes. Compreende-se que educar é assegurar o desenvolvimento a todos, em todas as dimensões, incluindo a intelectual, a física, a afetiva, a social e a simbólica, visão que contrapõe à ideia tradicional que a educação se estende ao processo escolar fixado no conhecimento acadêmico.

O espaço escolar voltado à escola normal ou a tradicional, muitas vezes, não é o suficiente para assegurar o conjunto de aprendizagens necessárias para que crianças, adolescentes, jovens e adultos consigam enfrentar os impasses sociais na contemporaneidade (SANTOS; PEREIRA; MELLO, 2019; MENEZES, 2012; RIBETTO; MAURÍCIO, 2009). A escola integral oferece novos métodos ao desafio de educar no século XXI. Direcionado a uma demanda, a educação integral oferece processos educacionais que cruzam a experiência escolar com a experiência da vida na sociedade e torna uma responsabilidade de todos. É preciso compreender os estudantes como o centro do processo de ensino-aprendizagem, e, assim, entender que cada um é único, com ritmo e estilo próprios. A equipe escolar, de forma coletiva, deve viabilizar um processo educativo planejado e organizado. $O$ objetivo do trabalho é elencar e descrever os caminhos que levam a educação em tempo integral, enfatizando-se que deve ser acessível à todos os educandos.

\section{DESENVOLVIMENTO}

\subsection{POLÍTICAS PÚBLICAS DE EDUCAÇÃO}

O Plano de Desenvolvimento da Educação (PDE) do ano de 2007, concebido como política pública do Estado, validado pela Lei Complementar no 130, de 14 de julho de 2010, tem como função o aprimoramento da educação básica no Brasil (SAVIANI, 2007; VOSS, 2011; CAMARGO; PINTO; GUIMARÃES, 2008). Uma das grandes ações é o Programa Mais Educação (PME), que promove o aumento da jornada 
escolar, e, assim, propõe a inclusão do programa de educação integral em todas as escolas do país. No ano de 2007, o Governo Federal lançou, no mês de abril, o Plano de Desenvolvimento da Educação (PDE), e tinha como propósito encontrar meios constitucionais para instaurar uma Política Nacional de Educação, com o intuito de garantir uma educação de qualidade inclusiva, que ajudasse na construção de autonomia dos alunos e o respeito às diversidades. Baseia-se em meios direcionadores, sendo eles a educação básica, a educação superior, a educação profissional e a alfabetização.

Composto por programas e ações, e, aqui, encaixa-se o Programa Mais Educação, almeja-se alimentar a educação integral a partir de atividades sócio educativas no período oposto a sala de aula (SANTOS; PEREIRA; MELLO, 2019; MENEZES, 2012; RIBETTO; MAURÍCIO, 2009). O financiamento seria advindo das ações do programa mediado pelo Fundo de Manutenção e Desenvolvimento da Educação Básica (FUNDEB) que sustenta a educação. Trata-se de um financiamento da Educação Básica e inclui a valorização dos profissionais da educação, abrindo um espaço para a educação integral. Para sustentar todos os Programas de Educação Integral, os mesmos deveriam ser mantidos. Fernandes, (2014) ressalta o valor do (FUNDEB) e a importância da valorização dos profissionais da educação. Esse tipo de ensino passou a ser mais comum após o decreto de 13 de novembro de 2007, № 6.253, que assegura recursos para a educação básica pública.

E, em seguida, surgiu a portaria 873, de 01 de julho do ano de 2010, que assegura 0 financiamento da educação integral com o FUNDEB. A oferta de tais finanças, provindas do PDDE, fez com que as escolas pudessem realizar alguns investimentos, como melhorar a sua infraestrutura e aperfeiçoar as suas práticas pedagógicas, representadas pelos professores, e, dessa forma, com a oferta recebida, tanto em termos administrativos quanto pedagógicos, podia-se almejar a educação progressiva para melhorar os índices de aprendizagem na educação básica (DAVIES, 2006; SENA, 2008; ROSEMBERG, 2010). O dinheiro e repassado as escolas por transferência, baseava-se, para tanto, no número de alunos matriculados e levava-se em consideração o censo escolar do ano anterior, sem precisar recorrer a convênios 
ou projetos, dentre outros (SAVIANI, 2007; VOSS, 2011; CAMARGO; PINTO; GUIMARÃES, 2008).

Pinheiro (2012), reitera que com o passar do tempo, o PDDE se responsabilizou pelo recebimento de recursos, e, dessa forma, passou a considerar inúmeras modalidades e programas parecidos que versam sobre a permanência no meio escolar público: PDDE Educação Integral, o PDDE Funcionamento das Escolas nos Finais de Semana (FEFS), o PDDE Escola Campo, o PDDE Água na Escola, o PDDE Escola Acessível, Plano de Desenvolvimento da Escola (PDE Escola) e o Programa Ensino Médio Inovador (ProEMI). Pinheiro (2012) frisa que cada unidade receptora deve se ater ao fato de que o valor recebido deverá ser usado como fonte de custeio para necessidades diversas, como, por exemplo, a compra de materiais de consumo e materiais pedagógico. Aponta, também, que a aquisição de recursos deve ser algo permanente. França (2005) afirma:

A gestão educacional, na visão descentralizadora envolve a participação da comunidade escolar e local na tomada decisões, especialmente no planejamento, execução e avaliação das atividades e também no exercício da autonomia pedagógica, administrativa e financeira do sistema de ensino (FRANÇA, 2005, p. 140).

França (2005) alude que os recursos recebidos devem ser discutidos e colocados em voga a partir de uma conversa com todos que integram o espaço da escola, pensar no momento certo para tal aplicação e na melhor forma são pautas essenciais, visando o atendimento à demanda da instituição escolar, almejando a efetivação da gestão democrática (PARO, 2007; LIMA, 2002; SOUZA, 2009). É uma forma de estender o compromisso à todos para que os interesses da comunidade escolar sejam atendidos. A presença do conselho escolar é indispensável. França (2005), em sua pesquisa, coloca que a destinação e o veredito final de como aplicar o recurso deve acompanhar as determinações do FNDE e do PDDE. A autonomia deve fazer parte das decisões sugeridas pelos membros que formam a escola e pelas deliberações sobre custeio do PDDE, adquirindo, assim, uma "autonomia decretada" que prioriza as unidades escolares, apontando os melhores usos para tais recursos. 
A direção de recursos financeiros deve estar sempre alinhada aos objetivos de interesse geral, de maneira a garantir a efetiva participação de todos os componentes do espaço escolar, garantindo-se, ainda, o compromisso social e a realização de um trabalho alinhado aos desejos dos atores que compõem a escola no que tange o financiamento da educação, o que requer o desenvolvimento de estratégias que asseguram a participação completa dos membros do conselho escolar na busca de uma educação de qualidade no contexto da instituição de ensino a qual fazem parte. França (2005, p. 153) assinala que "a tomada de decisões na alocação de recursos para as despesas significa optar, dentro de um elenco de possibilidades, entre o que se pode e o que não se deve gastar com os recursos do Salário-educação da Quota Federal, liberados pelo FNDE/MEC". Cardoso (2009), por sua vez, entende que as contribuições do PDDE fomentam a democratização da autonomia escolar.

Sobre o objetivo do programa, cabe auferir que o mesmo requer a presença de uma ideia política, burocrática, presente dentro das normas de descentralização e autonomia ao se tratar de recursos recebidos, e, dessa forma, cabe a discussão sobre a descentralização, já que todo o processo de implantação do programa é imposto por maneiras e meios de organização estabelecidos por lei a partir do FNDE. Assim sendo, cabe destacar, aqui, que a autonomia que tanto se almeja no meio escolar se esbarra nas exigências, e, ainda, a criação das unidades executoras é quem fomenta o direito aos repasses do dinheiro, acreditando-se, então, que é esse repasse que acarreta a obtenção de sucesso da escola no que tange 0 atendimento às necessidades de primeira linha que emergem no cotidiano escolar por meio da verba recebida (LECLERC; MOLL, 2012; SILVA; SILVA, 2013; PENTEADO, 2014; DAVIES, 2006; SENA, 2008; ROSEMBERG, 2010).

Define-se como educação integral, de maneira simples e peculiar, que ela ocorre e se manifesta quando a escola visa atender o aluno na integralidade ou na totalidade para oferecer o desenvolvimento da criança na jornada escolar, estendendo o espaço escolar apropriado para sua aprendizagem (SANTOS; PEREIRA; MELLO, 2019; MENEZES, 2012; RIBETTO; MAURÍCIO, 2009). O aluno é o alvo na escola para o desenvolvimento de suas habilidades de aprendizagem em sua vida 
escolar. Objetiva-se, então, um ensino de qualidade que possa garantir o aprender na escola e na vida da criança. Tais anseios são assegurados pela Constituição Federal (1988):

Art. 205. A educação, direito de todos e dever do Estado e da família, será promovida e incentivada com a colaboração da sociedade, visando ao pleno desenvolvimento da pessoa, seu preparo para o exercício da cidadania e sua qualificação para o trabalho. Art. 206. O ensino será ministrado com base nos seguintes princípios: I - Igualdade de condições para o acesso e permanência na escola; II - Liberdade de aprender, ensinar, pesquisar e divulgar o pensamento, a arte e o saber; III Pluralismo de ideias e de concepções pedagógicas, e coexistência de instituições públicas e privadas de ensino; IV - Gratuidade do ensino público em estabelecimentos oficiais; $\mathrm{V}$ - Valorização dos profissionais do ensino, garantido, na forma da lei, plano de carreira para o magistério público, com piso salarial profissional e ingresso exclusivamente por concurso público de provas e títulos, assegurado regime jurídico único para todas as instituições mantidas pela União; V - Valorização dos profissionais do ensino, garantidos, na forma da lei, planos de carreira para o magistério público, com piso salarial profissional e ingresso exclusivamente por concurso público de provas e títulos; (Redação dada pela Emenda Constitucional ํo 19, de 1998) V - Valorização dos profissionais da educação escolar, garantidos, na forma da lei, planos de carreira, com ingresso exclusivamente por concurso público de provas e títulos, aos das redes públicas; (Redação dada pela Emenda Constitucional № 53, de 2006) VI - Gestão democrática do ensino público, na forma da lei; VII - garantia de padrão de qualidade. VIII - piso salarial profissional nacional para os profissionais da educação escolar pública, nos termos de lei federal. (Incluído pela Emenda Constitucional no 53, de 2006) Parágrafo único. A lei disporá sobre as categorias de trabalhadores considerados profissionais da educação básica e sobre a fixação de prazo para a elaboração ou adequação de seus planos de 
carreira, no âmbito da União, dos Estados, do Distrito Federal e dos Municípios. (Incluído pela Emenda Constitucional no 53, de 2006) Art. 227. É dever da família, da sociedade e do Estado assegurar à criança e ao adolescente, com absoluta prioridade, o direito à vida, à saúde, à alimentação, à educação, ao lazer, à profissionalização, à cultura, à dignidade, ao respeito, à liberdade e à convivência familiar e comunitária, além de colocá-los a salvo de toda forma de negligência, discriminação, exploração, violência, crueldade e opressão.

Conforme a literatura (SANTOS; PEREIRA; MELLO, 2019; MENEZES, 2012; RIBETTO; MAURíCIO, 2009), a lei no 9089/1990, do Estatuto da Criança e Adolescente (ECA), discorre sobre a educação integral e a sua importância. Nesse dispositivo em questão é possível visualizar a contribuição da escola integral na formação do indivíduo. No Art. 53 assegura-se à criança e ao adolescente o direito:

[...] à educação, visando ao pleno desenvolvimento de sua pessoa, preparo para o exercício da cidadania e qualificação para o trabalho, assegurando se Ihes: I - Igualdade de condições para o acesso e permanência na escola; II - Direito de ser respeitado por seus educadores; III - Direito de contestar critérios avaliativos, podendo recorrer às instâncias escolares superiores; IV - Direito de organização e participação em entidades estudantis; V - Acesso à escola pública e gratuita próxima de sua residência. Parágrafo único. É direito dos pais ou responsáveis ter ciência do processo pedagógico, bem como participar da definição das propostas educacionais. (Estatuto da Criança e do Adolescente, Art, 53, 1990).

A lei de o 9394/1996, que instituiu a Lei de Diretrizes e Bases (LDB), assegura a implementação da educação integral no Brasil, sobretudo o Art. 34오 $\S 2$, que responsabiliza o Estado pela oferta do ensino em tempo integral de maneira progressiva. 
Art. 34. A jornada escolar no ensino fundamental incluirá pelo menos quatro horas de trabalho efetivo em sala de aula, sendo

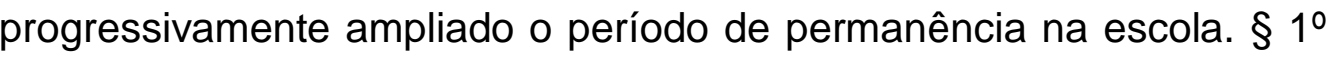
São ressalvados os casos do ensino noturno e das formas alternativas de organização autorizadas nesta lei. § 2으 O ensino fundamental será ministrado progressivamente em tempo integral, a critério dos sistemas de ensino.

Segundo Freitas (2009, p.21), "as políticas públicas se expressam por leis, regulamentos, orçamentos e se traduzem em diretrizes governamentais, voltadas para a garantia dos direitos sociais de todos os cidadãos". Castro (2001), por sua vez, enfatiza que:

[...] entidade autônoma e descentralizada da administração pública, com patrimônio constituído de recursos próprios, e criada por lei para executar serviços de caráter estatal e de interesse da coletividade tornando possível a unificação da política de gasto para o ensino fundamental e permitindo comprimir gastos de pessoal e de custeio operacional (CASTRO, 2001 p. 87).

A cooperação, interação e a comunicação são fundamentais ao bom funcionamento da Rede de Formação pela Escola, e, assim, atuam como meio eficaz para que se atinja os objetivos da proposta planejada, considerando as diretrizes do Programa em âmbito nacional. Segundo Moreira e Rizzoti (2009, p. 15), "para cumprir esta finalidade, a escola organiza sua gestão com base em um conjunto de normas e procedimentos provenientes do sistema de administração pública da educação ao qual está vinculada".

\subsection{EDUCAÇÃO INTEGRAL NO BRASIL}

A educação, no Brasil, ensejou-se com os jesuítas que lecionavam em colégios para os filhos dos feudais e a catequese era oferecida às classes menos favorecidas. Ressaltando que, no Brasil, a educação começou a ser motivo interesse do governo 
no mandato de Getúlio Vargas, no ano de 1930, momento em que acontece a transposição do modelo agrário exportador para o modelo agrário-industrial, nascendo, portanto, um novo cenário econômico. Com a nova economia, a educação passou a ser vista sobre outra ótica: era associada ao processo de industrialização, e, assim, preparava-se a mão de obra entendida como barata e com pouca qualificação para amenizar a necessidade de mercado. Com a Revolução de 1930, o processo escolar passou por mudanças expressivas, em razão das reformas ocorridas em vários estados. Alguns nomes são importantes: São Paulo, representado por Sampaio Dória (1920), Ceará, representado por Lourenço Filho (1923), Bahia, representada por Anísio Teixeira (1925), Minas Gerais, representada por Francisco Campos e Mario Casassanta (1927) e, por fim, Brasília, representada por Fernando de Azevedo (1928).

Anísio Teixeira é um nome essencial quando se discorre sobre educação como um todo, visto que foi responsável pelo Manifesto dos Pioneiros da Escola Nova, no ano de 1932 e, dessa forma, é conhecido por ser um forte defensor da educação. As suas ideias fomentaram um novo Sistema Público de Ensino (SANTOS; PEREIRA; MELLO, 2019; MENEZES, 2012; RIBETTO; MAURÍCIO, 2009). Assegurava e defendia a educação como meio de reestruturação nacional dentro da educação pública obrigatória e leiga, adaptada às características culturais e estaduais para atender aos interesses dos alunos em seus mais diversos níveis de aprendizado. Visava, dessa forma, a importância da educação para se viver em sociedade. Suas atitudes e pensamentos voltam-se à formação integral da vida humana, herança trazida de sua formação nas mais diversas universidades e áreas. Anísio Teixeira defendia uma filosofia baseada sempre na verdade, com aparatos na ciência.

Ele se baseia nas ideias de John Dewey, e, assim, tinha como objetivo a implementação de uma nova tendência acerca da existência humana, e, para tanto, apoiava-se nas questões pertinentes à esfera da educação, pois, segundo Anísio Teixeira, é a educação quem fomenta a vivência em mundo mais igualitário e que prioriza a integridade do ser humano. Nasceu dessas ideias o Sistema Público de Ensino no Brasil, sobretudo para estudantes que, historicamente, sempre tiveram o 
acesso negado à educação (SANTOS; PEREIRA; MELLO, 2019; MENEZES, 2012; RIBETTO; MAURíCIO, 2009). Ele elaborou diversos livros sobre a temática da educação e participou na elaboração da Lei de Diretrizes e Bases da Educação Nacional. Lutou arduamente em defesa da educação pública, e, dentre as suas principais obras, destacam-se "A educação e a crise brasileira", de 1956, e "Educação não é privilégio", de 1957.

Sofreu perseguições por bispos brasileiros e no ano de 1958 foi acusado de extremista e, dessa forma, foi demitido do governo federal. No governo de Juscelino Kubitschek foi exilado da vida pública, e, então, passou a ajudar a Organização das Nações Unidas para a Educação, a Ciência e a Cultura (UNESCO) a mando do governador da Bahia e, após, assumiu a Secretaria de Educação e Saúde. Nesse período inaugurou-se o Centro Popular de Educação Carneiro Ribeiro, Escola-Parque, situado no bairro da Liberdade, Salvador. Estudantes tinham acesso à educação integral, recebiam alimentação e eram feitas atividades de socialização e preparo para a vida social. Conseguiu realizar seu sonho na área da educação. As ideias do Centro Educacional Carneiro Ribeiro expandiram-se para as demais escolas do país. Anísio almejou a educação em tempo integral para que se valorizasse a formação humana que deveria tomar forma a partir de atividades variadas a serem desempenhadas ao longo do dia (SANTOS; PEREIRA; MELLO, 2019; MENEZES, 2012; RIBETTO; MAURÍCIO, 2009).

Teixeira (1997), almejava uma educação escolar com atividades e currículos da vida prática, que formasse atitudes da vida real, e, dessa forma, imaginava uma miniatura da sociedade. Nesse sentido, esse tipo de escola deve abranger atividades que valorizem as mais diversas dimensões da vida humana (SANTOS; PEREIRA; MELLO, 2019; MENEZES, 2012; RIBETTO; MAURÍCIO, 2009). Elas deveriam ser oferecidas em dois turnos. Entretanto, um dos maiores desafios ainda hoje é a falta de recursos, de capacitação profissional e de um espaço adequado para que a formação seja, de fato, integral. A proposta é defendida pois foi a partir das ideias de Anísio Teixeira que as classes mais desfavorecidas tiveram acesso à uma educação de qualidade. Foi a 
partir das atividades desempenhadas no Centro Carneiro Ribeiro que outras escolas passaram a almejar essa modalidade. Ela funcionava da seguinte forma:

A escola primária seria dividida em dois setores, o da instrução, propriamente dita, ou seja, da antiga escola de letras, e o da educação, propriamente dita, ou seja, da escola ativa. No setor instrução, manterse-ia trabalho convencional, o da classe, o ensino de leitura, escrita e aritmética e mais ciências físicas e sociais, e no setor educação - as atividades socializantes, a educação artística, o trabalho manual e as artes industriais e a educação física (TEIXEIRA, 1962, p. 82).

O Centro seria composto por salas, cada qual em suas funções distintas, ou seja:

(...) escolas-classes, isto é, escolas de ensino de letras e ciências (...) escola-parque onde se distribuiriam as outras funções do centro, isto é, as atividades sociais e artísticas, as atividades de trabalho e as atividades de educação física. A criança fará um turno na escola-classe e um segundo turno na escola parque. Nesta escola, além de locais para as suas funções específicas, temos mais a biblioteca infantil, dormitórios para 200 das 4000 crianças atendidas pelo Centro e os serviços gerais e de alimentação. (...) Além da reforma da escola, temos o acréscimo desse serviço de assistência alimentar. Cinco por cento dentre elas receberão mais o internato. Serão crianças chamadas propriamente de abandonadas, sem pai e sem mãe, que passarão a ser não as hóspedes infelizes e tristes de orfanatos, mas as residentes da escola-parque, às quais competirá a honra de hospedar as suas colegas, bem como a alegria de frequentar com elas as escolas classe. (TEIXEIRA, 1962, p. 83).

As atividades tradicionais, historicamente vistas como escolares, aconteceriam nas Escolas-Classe e as outras atividades diversificadas no contraturno. Assim sendo, não basta aumentar as horas desse educando na escola, é preciso garantir que todos os aspectos da vida humana estão sendo desenvolvidos. Devem estar aptos para 
exercer a cidadania de forma consciência e integrar o mercado de trabalho, porém, de igual importância são os momentos de esporte, cultura e lazer ao longo dessa jornada (SANTOS; PEREIRA; MELLO, 2019; MENEZES, 2012; RIBETTO; MAURÍCIO, 2009). É essa a escola integral em tempo integral desenhada por Anízio Teixeira. As turmas eram organizadas a partir da idade dos alunos. A Escola Parque contemplava uma educação integral projetada e desenhada para o alcance dos objetivos daquele contexto. $O$ alunado, além das disciplinas escolares, tinham contato com as artes plásticas; esportes; recreação; atividades de socialização, artísticas e culturais.

No projeto havia o planejamento par a construção desse espaço. Outro objetivo defendido é que ao menos cinco por cento dos alunos deveriam ser aqueles que não possuía moradia. Em uma primeira instância a escola visava integrar esse aluno com a comunidade escolar a partir de atividades que privilegiavam a comunicação entre os alunos. Visava-se formar mentes críticas e conscientes acerca dos seus direitos e deveres, sendo o principal desafio fazer com que esses alunos estivessem aptos a exercer a cidadania social. Preocupações sobre a formação de professores já eram comuns à época e continuam como um entrave à modalidade até os dias atuais (SANTOS; PEREIRA; MELLO, 2019; MENEZES, 2012; RIBETTO; MAURÍCIO, 2009). As atividades oferecidas privilegiavam, ainda, os hábitos para uma vida saudável. Deve-se ressaltar, ainda, que:

É contra essa tendência a simplificação destrutiva que se levanta esse Centro Popular de Educação. Desejamos dar de novo a escola primária o seu dia letivo completo. Desejamos dar-Ihe os seus cinco anos de curso. E desejamos dar-lhes seu programa completo de leitura, aritmética e escrita, e mais ciências físicas e sociais, e mais artes industriais, desenho, música, dança e educação física. Além disso, desejamos que a escola eduque, forme hábitos, forme atitudes, cultive aspirações, prepare realmente a criança para a sua civilização - esta civilização tão difícil por ser uma civilização técnica e industrial e ainda mais difícil e complexa por estar em mutação permanente. E, além disso, 
desejamos que a escola dê saúde e alimento à criança, visto não ser possível educá-la no grau de desnutrição e abandono em que vive [...] a escola primária será algo que lembre uma pequenina universidade infantil (TEIXEIRA, 1951, pp. 141 e 146).

A Educação Integral, segundo Anísio Teixeira, solucionava muitos problemas sociais da época. Nesse contexto, o Centro Educacional Carneiro Ribeiro se candidatava para ser o modelo defendido de educação: "Foi com o objetivo de oferecer um modelo para esse tipo de escola primária que se projetaram na Bahia o Centro Carneiro Ribeiro, que constitui a primeira demonstração" (TEIXEIRA, 1962 p.25). Em 1960, Anísio Teixeira, então gestor do INESP, a mando de Juscelino Kubitschek de Oliveira, passou a gestar o "Plano Humano" e tinha como ajudante Darcy Ribeiro e Cyro dos Anjos. Organizado pela comissão, o Sistema Educacional de Brasília era um modelo educacional para o país, que deveria se manifestar em nível educacional elementar, e, assim, pensaram num modelo de educação integral amparado no modelo de Salvador, porém mais sofisticado. Passou-se a operar a partir do Escola-Classe com Jardins de Infância.

Havia uma quadra na Escola-Parque para acolher os alunos no contra turno. Já a Escola-Classe foi projetada para que o desenvolvimento de atividades físicas, esportivas, artísticas e culturais deixasse o plano das ideias e se tornasse uma realidade nesses espaços. A estrutura foi arquitetada pelo famoso arquiteto Oscar Niemeyer e tinha um espaço físico invejável e único, capaz comportar até 30.000 pessoas nas quatro quadras. A escola integral teve outro fato histórico importante na década de 1980, no estado do Rio de Janeiro, com Darcy Ribeiro, que instituiu os CIEPs - Centros Integrados de Educação Pública, amparando-se na ideologia de Anísio Teixeira (SANTOS; PEREIRA; MELLO, 2019; MENEZES, 2012; RIBETTO; MAURÍCIO, 2009). Criou-se quinhentas e seis escolas nos dois governos de Leonel Brizola, arquitetadas por Oscar Niemeyer e batizadas como "Escola Integral em horário integral". Ressalta Darci Ribeiro (1986) que:

O CIEP é uma escola que funcionava das 8 horas da manhã até às 5 horas da tarde, com capacidade de abrigar 1.000 alunos (...). No bloco 
principal com três andares estão as salas de aula, um centro médico, a cozinha e o refeitório, além das áreas de apoio e recreação. No segundo bloco, fica o ginásio coberto, com sua quadra de vôlei/basquete/futebol de salão, arquibancada e vestiário. Esse ginásio é chamado de salão polivalente, porque também é usado para apresentações teatrais, shows de música, festa, etc. No terceiro bloco de forma octogonal, fica a biblioteca e, sobre ela, as moradias para alunos-residentes (RIBEIRO, 1986, p. 42).

Com a Portaria Normativa Interministerial o 17 e oㅜ 19, do dia 24 de abril do ano de 2007, instituiu-se o Programa Mais Educação (LECLERC; MOLL, 2012; SILVA; SILVA, 2013; PENTEADO, 2014). Ele, por sua vez, concebeu o Plano de Ações Articuladas (PAR), a ser executado pelos estados e municípios para o acolhimento de doações e para receberem ajuda técnica do MEC. O olhar sobre a educação integral, segundo o MEC, é o seguinte:

Art.1ํInstituir o Programa Mais Educação com o objetivo de contribuir para formação integral de crianças adolescentes e jovens por meio da articulação de ações, de projetos e de programas do Governo Federal e suas contribuições às propostas, visões e práticas curriculares da rede pública de ensino e das escolas, alterando o ambiente escolar e ampliando a oferta de saberes, métodos, processos e conteúdos educativos: Parágrafo único: O programa será implementado por meio do apoio à realização em escolas e outros espaços socioculturais, de ações socioeducativas no contra turno escolar, incluindo os campos da educação, artes, cultura, esporte, lazer, mobilizando-os para a melhoria do desempenho educacional [...] (Ministério da Educação, 2009, p. 14).

Portanto, o Programa Mais Educação sustenta a ideia de que é necessário implantar a educação integral objetivando, para tanto, a formação integral "como meio de assegurar o desenvolvimento em todos os âmbitos da condição humana" (Ministério da Educação, 2009, p. 42). Uma vez que a escola integral tem se popularizado em todo o país, é preciso, entretanto, enfatizar a necessidade de se formar cidadãos em 
suas mais diversas dimensões, enfocando no direito de ir e vir e, ainda, em seus direitos e deveres enquanto cidadãos brasileiros (LECLERC; MOLL, 2012; SILVA; SILVA, 2013; PENTEADO, 2014).

\subsection{PROFESSORES, PROPOSTAS E POSSÍVEIS SOLUÇÕES}

Para assegurar uma educação de qualidade o MEC se juntou a vários órgãos, como, por exemplo, ao Fundo Nacional de Desenvolvimento da Educação (FNDE). Segundo Moreira e Rizzoti (2009, p. 40): "compete ao FNDE à função redistributiva da contribuição social do salário-educação". Dessa forma, 10\% são direcionados a programas, projetos e ações voltados à igualdade da educação básica. Ao falar em educação integral no país cabe auferir que ela tem evoluído bastante, porém as dificuldades para a sua implementação efetiva ainda são muitas. Destacam-se, dentre elas, questões relativas ao processo de gestão do ensino e planejamento, a escassez de materiais e recursos didáticos, a ausência da formação continuada dos professores, a não correlação entre a teoria e a prática e a falta de aplicação de um currículo adequado. Esses fatores impedem a plena efetividade da educação em tempo integral.

A articulação, a improbidade carregada pelos alunos à escola, às dificuldades no domínio da leitura e escrita e na compreensão do saber do raciocínio logicomatemático, questões sobre a natureza e sociedade, as avaliações aplicadas e as questões de gênero são algumas dessas dificuldades. É preciso ressaltar, também, que problemas relacionados ao ensino integral, ao processo de planejamento e ao fato de que os professores não consideram o perfil dos alunos e a falta de adequação de práticas à individualidade e à capacidade de cada aluno impedem essa eficiência. Pode-se destacar, ainda, o planejamento inadequado, falta de experiência com o diferente e má formação do professor, o que motiva experiências desastrosas. O planejamento direciona a educação dentro do processo de decisão, como frisa o documento do Ministério da Educação (2009, p. 18):

A Educação Integral constitui ação estratégica para garantir proteção e desenvolvimento integral às crianças e aos adolescentes que vivem na 
contemporaneidade marcada por intensas transformações: no acesso e na produção de conhecimentos, nas relações sociais entre diferentes gerações e culturas, nas formas de comunicação, na maior exposição aos efeitos das mudanças em nível local, regional e internacional.

A prática pedagógica relacionada aos objetivos planejados faz com que o professor consiga chegar a uma aprendizagem efetiva e significativa dentro do planejado, aguçando a permanência do aluno na escola, e, ainda, esse trabalho favorece o sistema educacional e a avaliação constante da atuação do professor em sala de aula. Porém gestar em sala de aula, nesse âmbito, ainda é algo dificultoso, o que afeta a qualidade do ensino ofertado. Não se trata de culpar a organização didáticapedagógica do ensino integral, contudo, a modalidade deve atender ao perfil dos alunos para não inibir os processos educativos almejados. O profissional se depara com as indiferenças em sala de aula, e, assim, deve ser capaz de focar além dos conteúdos programáticos, não ser um simples executor de tarefas, mas sim atuar de forma reflexiva, como apontado por Anísio Teixeira:

Educação é vida, e viver é desenvolver-se é crescer. Vida e crescimento não estão subordinados a nenhuma outra finalidade, salvo mais vida $e$ mais crescimento. $O$ processo educativo, portanto, não tendo nenhum fim, além de si mesmo, é o processo de contínua reorganização, reconstrução e transformação da vida, e fazer com que as condições da vida sejam tais que todos aprendam no processo de viver, é o processo mais rico que pode a escola alcançar. Graças a esse hábito, a educação como reconstrução contínua da experiência, fica assegurada como o atributo permanente da vida humana (TEIXEIRA, 1994, p .49).

A reflexão faz parte de sua atuação em sala de aula, pois é ela quem viabiliza a construção do conhecimento na prática pedagógica, e, assim, o docente precisa ser aberto para o ao novo, as mudanças, e, ainda, dedicar-se ao trabalho e ter comprometimento com seu discente, para, assim, conseguir melhorar o desenvolvimento na área da aprendizagem. Ambrósio (1998), frisa que o compromisso do professor vai muito além da disciplina em que atua e se formou, e, 
dessa forma, esse profissional precisa formar a cidadania do aprendiz. Por isso, o professor é o construtor responsável para o crescimento intelectual e pessoal de seus alunos.

Nesse contexto, cabe auferir, considerando a responsabilidade do professor, que esse profissional, dentre outros objetivos essenciais à prática pedagógica-didática, deve ter o domínio de técnicas e metodologias para que consiga adentrar no mundo dos educandos e leva-los a compreender que a sede por conhecimento ajuda para melhorar a qualidade de suas vidas. Os materiais didático-pedagógicos e os recursos ainda são escassos, e, assim, os professores encontram dificuldades para ministrar essas aulas em tempo integral com sucesso, o que faz com que, em muitos momentos, não haja aproximação dele com a realidade dos alunos e o processo de ensino e aprendizagem se torna insignificante, como ressalta Sacristan (1998):

Exige-se dos currículos modernos que, além das áreas clássicas do conhecimento, deem noções de higiene pessoal, de educação para o trânsito, de educação sexual, educação para o consumo, que fomentem determinados hábitos sociais, que previnam contra as drogas, que se abra para novos meios de comunicação, que respondam às necessidades de uma cultura juvenil com problemas de integração no mundo adulto, que atendam aos novos saberem científicos e técnicos, que acolham o conjunto das ciências sociais, que recuperem a dimensão estética da cultura, que se preocupem pela deterioração do ambiente, etc (SACRISTAN, 1998, p. 58).

Apoiado no currículo, o professor deve se posicionar como um agente transformador, motivando seus alunos na melhoria constante de conhecimento, e, dessa forma, precisa ir além da teoria, adentrar sempre na prática e proporcionar esse conhecimento aos seus alunos para que consigam ter uma relação de teoria com a prática no dia a dia.

Ensinar exige respeito aos saberes dos educandos [...], discutir com os alunos a razão de ser de alguns desses saberes e relação com o ensino 
dos conteúdos [...]. Ensinar exige disponibilidade para o diálogo [...] ensinar exige o reconhecimento e a assunção da identidade cultural [...]. Ensinar exige a apreensão da realidade [...], transformar a realidade para nela intervir, recriando-a [...]. Ensinar exige segurança, competência profissional e generosidade [...]. O fundamental no aprendizado do conteúdo e a construção da responsabilidade, liberdade que se assume [...] (LEMOS, 1999, p. 20 apud FREIRE, 1996, pp. 7-8).

O professor exerce um papel primordial nas instituições de ensino, pois, ao receber o aluno, reconstrói a sua prática, e, assim, é preciso considerar toda a sua trajetória dentro da escola. Aceitar o aluno é fácil, mas respeitar as suas dificuldades e fornecer a ele condições de permanência na escola para que continue seus estudos é o principal . Assim: "saber que ensinar não é transferir conhecimento, mas criar possibilidades para a sua própria produção ou a sua construção" (FREIRE, 1996, p. 47). As dificuldades encontradas pelos professores não são poucas, pois, em muitas vezes, relacionar a ação educativa à uma ação social demanda a atuação de todos os envolvidos no processo de ensino-aprendizagem e isso exige que o aluno aja de forma ativa na sociedade em que vive.

[...] os educadores devem analisar e definir claramente a ação educativa, percebendo-a como uma ação social estabelecendo uma proposta que considere as relações escola-comunidade e o retrato cultural, produzindo uma prática educativa articuladora da teoria com a prática, tendo o educando como sujeito do processo de aprendizagem. (LEMOS, 1999, p. 19).

Dificuldades relacionadas à articulação do currículo e a sua elaboração e à ausência de objetivos claros, pois, em muitas vezes, não apresentam ou não atendem às expectativas e anseios de seus alunos, são frequentes e preocupantes. Segundo Lemos (1999), é preciso elencar a diversidade do público que se almeja e considerar alguns fatores na elaboração do currículo, e, assim, deve-se criar modelos que atendam aos anseios de seus alunos, o que implica a adequação de conteúdos considerando as características dos discentes, a distribuição e a seleção de 
conteúdos curriculares e a verificação dos objetivos da educação dentro de um processo de constante de reflexão. Incluir atividades voltadas à formação do aluno para a vida demanda um processo de ensino contínuo. É o ensino quem fomenta a formação do cidadão.

A proposta curricular deve ser múltipla e os temas que se referem à cultura, problemas e soluções ambientais e discussões sobre as relações sociais devem nortear o trabalho do docente, assim, assuntos capazes de integrar o aluno na sociedade são essenciais, além de atender às necessidades de aprendizagem. O professor e seus alunos devem ser capazes de lidar com meios diferentes de relacionamento, priorizando o acolhimento de todas as ideias em sala de aula. Freire (1996), em suas reflexões, frisa que o professor deve ser cuidadoso para não discriminar ou desfavorecer o aluno por algum motivo, já que o aluno tem de seu professor a percepção de sua postura em sala de aula, e, então, precisa estar atento à leitura que os alunos realizam do seu trabalho e à todas as situações vinculadas na sala de aula, desde um silêncio a um sorriso ou a uma saída da sala.

É preciso entender que o espaço pedagógico é um espaço de muita reflexão entre a relação estabelecida entre professor/ aluno. Nesse sentido, Freire, (1996, p. 97) frisa que: "quanto mais solidariedade exista entre o educador e o educando no 'trato' desse espaço, tanto mais possibilidades de aprendizagem democrática se abrem na escola". Assegurar a formação cidadã é essencial, e, dessa forma, o compromisso da escola é grande. Para tanto, a mesma precisa trabalhar aspectos que envolvam a sociedade e a natureza, elencando, nesse processo, valores, conhecimentos e habilidades, de forma a ajudar os alunos a compreenderem, criticamente, a realidade à sua volta. Nesse contexto, as informações devem ser de fácil entendimento e precisam se relacionar às vivências desse alunado.

Na mesma medida, fazer com que haja o interesse do aluno em descobrir contextos diferentes do seu também é um desafio. Oportunizar o acesso aos mais diversos tipos de informações deve predominar na prática pedagógica. O professor precisa ter em mente que o processo de formação do aluno não é seletivo, mas uma ação de reflexão, o que demanda a descoberta de dificuldades e apontar os pontos positivos 
de cada sujeito. Discutir sobre as questões de gênero quando abordar as relações entre homens e mulheres e reflexões sobre questões sobre a desigualdade e práticas sociais é crucial. Fazer uso de ferramentas diversas para realizar tais discussões ajudará na formação integral do indivíduo, pois os temas são transversais e farão com que esses alunos se aceitem e se sintam parte da sociedade.

\section{CONSIDERAÇÕES FINAIS}

Descobrir e perceber a necessidade das crianças e, a partir disso, redescobrir ou redesenhar novos caminhos para serem trilhados para aplicar e intervir novas estratégias é um grande desafio. Professores, escola e políticas públicas devem assumir a responsabilidade junto à sociedade, respeitando os objetivos da educação integral. É preciso acreditar na identidade dessa modalidade e garantir o seu pleno funcionamento. A educação integral requer e exige a centralidade escolar, e, para tanto, todos os alunos precisam ser desenvolvidos de forma ampla, e, ainda, as suas experiências de vida precisam ser respeitadas e resgatadas por essa escola. É essa a sua função. Do mesmo modo, o papel dos profissionais que a fazem a educação algo possível precisa ser, continuamente, repensado e renovado.

A abordagem política e filosófica da educação integral e a jornada ampliada nos permite entender que, de fato, a educação faz parte de uma sociedade civil, e, assim, a participação eficaz nas políticas públicas é essencial, pois é uma forma de assegurar uma educação planejada dentro dessas políticas, lembrando-se da visão social de mundo e de suas obrigações sociais. A importância desta pesquisa visa que a educação não pode fechar os olhos frente à escola integral, precisa conhecer que aprender implica muitas variantes, das mais variados possíveis. Assim, as origens, valores e sentimentos do alunado precisam ser respeitados no contexto escolar, o que implica a abordagem de fatos e acontecimentos da vida real nas atividades escolares e extracurriculares, o que implica uma organização sociopsicológica profunda.

Sabendo que as normas gerais de desenvolvimento são as mesmas para todo o alunado, enfatizar que são seres capazes e fomentar a busca contínua pelo conhecimento e desenvolvimento de novas habilidades são atitudes que se mostram 
urgentes. Entender esses sujeitos como agentes centrais do processo educativo e enfatizar a sintonia entre a escola e os alunos a partir de reflexões e intervenções é fundamental. Valorizar e incentivar a troca de conhecimento a partir dessas atividades também é indicado. Nesse sentido, a adaptação da escola integral é urgente, o que acarreta a abordagem de questões significativas ao seu funcionamento com as famílias desses alunos. O oferecimento de oficinas no contra turno é uma possibilidade para que a ampliação da jornada seja eficaz.

Priorizar a educação é um processo necessário, e, sobretudo, contínuo, e, dessa forma, o desenvolvimento de políticas públicas de modo periódico é importante para que o ensino em tempo integral fomente, de fato, a formação integral do ser humano. É preciso estar sempre atento à realidade que nos circunda e superar os próprios limites da gestão pedagógica. Nesse contexto, é de suma importância que o poder público contribua para com o aperfeiçoamento da educação em tempo integral a partir de projetos e ações voltados à educação como um todo, contribuindo, dessa forma, para com a diminuição da distância das pessoas da escola, enfatizando-se que todos devem ter acesso à uma educação de qualidade, priorizando, portanto, o desenvolvimento de todas as dimensões que dão vida ao ser humano.

\section{REFERÊNCIAS}

AMBRÓSIO, D. Tempo da escola e tempo da sociedade. In: SERBINO, R. V. et al. Formação de professores. São Paulo: Fundação Editora da Unesp, 1998.

ARELARO, L. R. G.; JACOMINI, M. A.; CARNEIRO, S. R. G. Limitações da participação e gestão "democrática" na rede estadual paulista. Educação \& Sociedade, v. 37, n. 137, p. 1143-1158, 2016.

BRASIL. Lei das Diretrizes e Bases da Educação Nacional. Brasília, 1996. Ministério da Educação. Cadernos Série Mais Educação - Educação Integral. Brasília, 2009. 
Ministério da Educação. Cadernos Série Mais Educação - Texto referência para o debate nacional. Brasília, 2009.

Ministério da Educação. Cadernos Série Mais Educação - Rede de Saberes.. Brasília, 2009.

Constituição da República Federativa do Brasil. Brasília, 1988.

Ministério da Educação. Plano de Desenvolvimento da Educação. Brasília, 200750

Estatuto da Criança e do Adolescente. Lei no 8.069, de 13 de julho de 1990.

CAMARGO, R. B. de.; PINTO, J. M. de. R.; GUIMARÃES, J. L. Sobre o financiamento no Plano de Desenvolvimento da Educação. Cadernos de pesquisa, v. 38, n. 135, p. 817-839, 2008.

DAVIES, N. FUNDEB: a redenção da educação básica? Educação \& Sociedade, v. 27, n. 96, p. 753-774, 2006.

FRANÇA, M. Gestão e Financiamento da Educação: o que mudou na escola? PDDE. FUNDEF. Natal: EDUFRN, 2005.

FREIRE, Paulo. Pedagogia da autonomia: saberes necessários à prática educativa. São Paulo: Paz e Terra, 1996.

FREITAS, K. S. Progestão: como articular a gestão pedagógica da escola com as políticas públicas da educação para a melhoria do desempenho escolar? Módulo X. Brasília: CONSED, 2009.

Fundo Nacional de Desenvolvimento da Educação (FNDE) Caderno de estudos do Curso Tutoria para a rede de Formação pela Escola/ Fundo Nacional de Desenvolvimento da Educação. $2^{\mathfrak{a}}$ ed. Brasília: FNDE, 2014. 
GHANEM, E. Educação escolar e democracia no Brasil. São Paulo: Ação Educativa, 2004.

LECLERC, G. de. F. E.; MOLL, J. Programa Mais Educação: avanços e desafios para uma estratégia indutora da Educação Integral e em tempo integral. Educar em Revista, n. 45, p. 91-110, 2012.

LEMOS, M. E. P. de. Proposta curricular. In: Salto para o futuro - Educação de jovens e adultos. Brasília, v. 10, p. 19-27, 1999.

LIMA, L. C. Organização escolar e democracia radical: Paulo Freire e a governação democrática da escola pública. 2ª ed. São Paulo: Cortez, 2002.

MENEZES, J. S. S. Educação em tempo integral: direito e financiamento. Educar em revista, n. 45, p. 137-152, 2012.

MOREIRA, A. M. de A.; RIZZOTI, J. R. Progestão: como gerenciar os recursos financeiros? Módulo VI. Brasília: CONSED, 2009.

PARO, V. H. Gestão escolar, democracia e qualidade do ensino. $2^{\underline{a}}$ ed. São Paulo: Intermeios, 2007.

PENTEADO, A. Programa Mais Educação como política de educação integral para a qualidade. Educ. Real, v. 39, n. 2, p. 463-486, 2014.

PEREIRA, V. S.; BATISTA, N. C. A gestão escolar democrática na formação inicial do professor: elementos teóricos para pensar a formação política do professor da educação básica. Educação e Formação, v. 1, n. 3, p. 71-87, set./dez. 2016.

SACRISTAN, G. O currículo: uma reflexão sobre a prática. Porto Alegre: Artmed, 2000.

SANTOS, C. C. de. F.; PEREIRA, R. da. S.; MELLO, M. B. de. Educação gerencial nas políticas públicas de Educação em Tempo Integral do governo Lula/Dilma ao governo Temer. Estudos IAT, v. 4, n. 2, p. 109-125, 2019. 
SAVIANI, D. O Plano de Desenvolvimento da Educação: análise do projeto do MEC. Educação \& Sociedade, v. 28, n. 100, p. 1231-1255, 2007.

SENA, P. A legislação do Fundeb. Cadernos de pesquisa, v. 38, n. 134, p. 319-340, 2008.

SILVA, J. A. de. A. da.; SILVA, L. N. P. A hegemonia às avessas no Programa Mais Educação. Revista Brasileira de Estudos Pedagógicos, v. 94, n. 238, p. 701-720, 2013.

SOUZA, A. R. de. Explorando e construindo um conceito de gestão escolar democrática. Educação em revista, v. 25, n. 3, p. 123-140, 2009.

RIBEIRO, D. Sobre os CIEPS. Coleção Encontros. Rio de Janeiro, 2007.

RIBETTO, A.; MAURÍCIO, L. V. Duas décadas de educação em tempo integral: dissertações, teses, artigos e capítulos de livros. Em Aberto, v. 22, n. 80, p. 137-160, 2009.

ROSEMBERG, F. Educação infantil pós-FUNDEB: avanços e tensões. Educar na infância: perspectivas histórico-sociais. São Paulo: Contexto, 2010.

TEIXEIRA, A. Educação não é privilégio. Rio de Janeiro: UFRJ, 1994.

Educação para a democracia. Rio de Janeiro: UFRJ, 1997.

Educação e a crise brasileira. Rio de Janeiro: UFRJ, 1999.

Centro Educacional Carneiro Ribeiro. Revista Brasileira de Estudos Pedagógicos, v. 31, n. 73, p.78-84, jan./mar. 1959.

Uma experiência de Educação Primária Integral no Brasil. Revista Brasileira de Estudos Pedagógicos, v. 38, n. 87, p .21-33, jul./set. 1962.

VOSS, D. M. da. S. O Plano de Desenvolvimento da Educação (PDE): contextos e discursos. Cadernos de Educação, n. 38, p. 43-67, 2011. 
ZEBINI, D. O que é educação integral? 2014. Disponível em: http://www.uniedu.sed.sc.gov.br/wp-. Acesso em: 10 mar. 2020.

Enviado: Março, 2020.

Aprovado: Junho, 2020. 